\title{
Design and Implementation of Three Phase Parallel DC - DC Converter for Low Power and Distribution Applications
}

\author{
M. Joly ${ }^{1} \&$ R. Ramaprabha ${ }^{2}$ \\ ${ }^{1}$ Department of Electrical Engineering, Saveetha Engineering College, Saveetha Nagar, Thandalam, Chennai, \\ Tamilnadu, India \\ ${ }^{2}$ Department of Electrical Engineering, SSN College of Engineering, Rajiv Gandhi Salai, Kalavakkam-603110, \\ Chennai, Tamilnadu, India \\ Correspondence: M. Joly, Department of Electrical Engineering, Saveetha Engineering College, Saveetha Nagar, \\ Thandalam, Chennai, India. Tel: 91-442-681-1499/599. E-mail: jolyhinoj@yahoo.co.uk
}

Received: November 11, $2014 \quad$ Accepted: November 18, $2014 \quad$ Online Published: March 1, 2015

doi:10.5539/mas.v9n4p193 URL: http://dx.doi.org/10.5539/mas.v9n4p193

\begin{abstract}
The steady state stability and performance characteristics of dc grid in electric power system used for low power and building applications are very crucial. When one converter alone extends power to all loads, life of the system is reduced due to increase in temperature, and there is limitation for expansion of capacity. These limitations are overcome by parallel functioning of bidirectional extended dc-dc converter. In this paper design and simulation of three phase parallel bidirectional dc-dc converter is discussed. The ability and performance of the system to get ripple reduction and steady state output is verified through simulation and experimentation. The design proposed can be used in de distribution system construction and low power applications.
\end{abstract}

Keywords: bidirectional dc-dc converter, buck-boost converter, dc distribution system, pulse width modulation

\section{Introduction}

A few techniques exist to accomplish dc-dc voltage conversion. Each of these routines has its particular own profits and hindrances, contingent upon various working conditions and details. Voltage conversion ratio range, the maximal yield power, power conversion efficiency, number of parts, power density, galvanic separation of data and yield, and so forth are some examples. At this point when outlining the complete incorporated dc-dc converters these details for the most part remain pertinent, all things considered some of them will put on weight, as more confinements rise. For example the utilized IC innovation, the IC engineering choices and the accessible chip region will be prevailing for the preparation cost, which confines the quality component of the passive segments (Woywode and Guldner et al., 2000). These restricted qualities will thus have a huge effect upon the decision of the conversion system (Jaber Abu-Qahouq and Issa Batarseh, 2000).

Dc-dc power converters are utilized in all mixture provisions, including power supplies for PCs, office utilities; space craft frameworks, telecommunications, computers, and additionally dc engine drives. The data to dc-dc converter is an uncontrolled dc voltage $\mathrm{V}_{\mathrm{g}}$. The converter processes a directed yield voltage $\mathrm{V}$, which have a magnitude that varies from $\mathrm{V}_{\mathrm{g}}$. For instance, in an elevator of power supply, $120 \mathrm{~V}$ or $240 \mathrm{~V}$ utility voltages is redressed, generating a dc voltage of more or less $170 \mathrm{~V}$ or $340 \mathrm{~V}$, individually. Dc-dc converter, when used with computers diminishes the voltage to the managed $5 \mathrm{~V}$ or $3.3 \mathrm{~V}$ needed by the processor ICs (Mohammad, 1993). High productivity is perpetually needed, since cooling of wasteful power converters are troublesome and unmanageable (Mohan Ned et al., 1995). The perfect dc-dc converter displays $100 \%$ proficiency; in actual practice, efficiencies of $70 \%$ to $95 \%$ are normally acquired. The chopper circuits whose components disperse immaterial power are utilized for this (Adel, 2006).

In this paper, an application of three phase parallel connected dc-dc converter in distribution of load for building applications is designed. The ripple reduction has been achieved via proper PWM technique and the ability of ' $\mathrm{m}$ ' phase proposed converter arrangement has been validated through experimentation. The following sections describe the design structure and hardware implementation (Williams, 1992).

With the fast development of electronic system, the disadvantage of dc power system, such as voltage degeneration has minimized. Also according to growth in renewable energy, dc power system has been taken its 
position when compared to ac power system. Also due to advantage of unity power factor, lack of frequency, made dc power system more advantageous. In case of dc conversion method, double stage power conversion can be avoided, which is there in ac power system. This dc-dc converter has an advantage that it avoids the use of conventional three phase isolated high frequency transformer. Also the filters at the output and input stages, makes the switching frequency, three times, which will reduce the ripple current.

\section{Description of the Parallel Connected DC-DC Converter}

For building applications, dc distribution system is fed from $380 \mathrm{~V}_{\mathrm{rms}}$. As dc-dc converter system is of boost type, the output is $650 \mathrm{~V}_{\mathrm{dc}}$. Distribution voltage is $380 \mathrm{~V}_{\mathrm{dc}}$ and it is achieved by combining buck-boost bidirectional power converter. To improve transient stability, the parallel connection of converter is used. By sharing the current in three phases, the switching frequency can be improved. The flow of current in buck and boost mode for dc-dc converter is showed in Figure 1. Switches of each phase are operated simultaneously through control. In buck mode flow of current is from source to load and in boost mode flow of current is from load to source (Chi-Hwan et al, 2012).

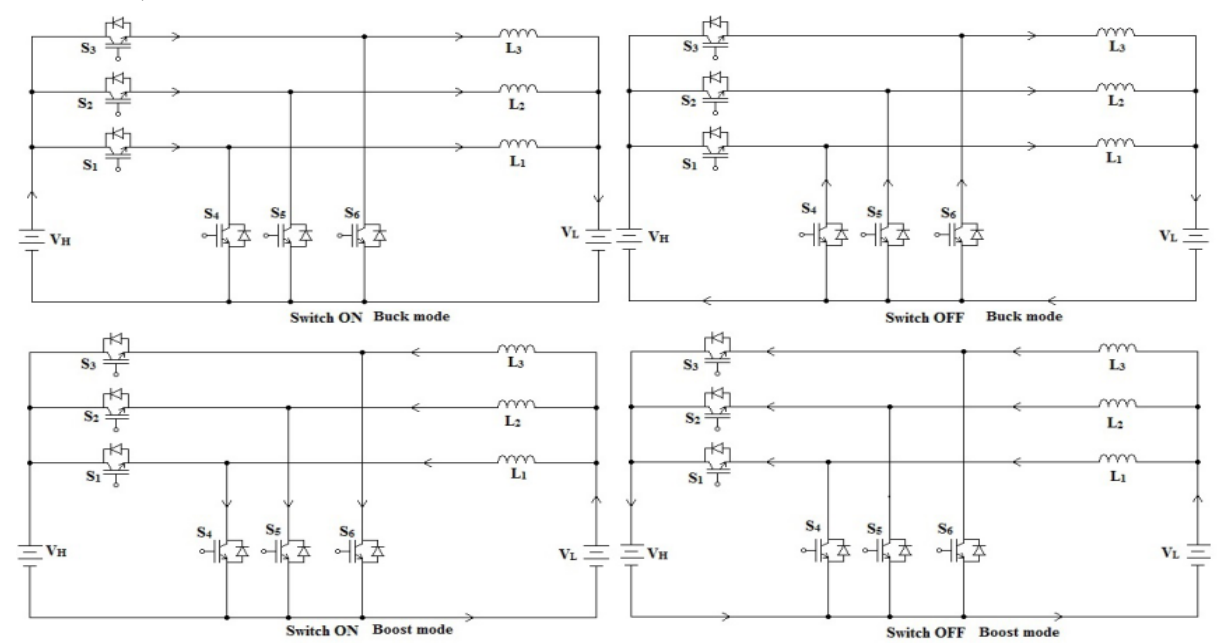

Figure 1. Modes of operation of three phase dc-dc converter

Figure 2 shows the block diagram of a de distribution system. Substantial obligation supplies could be worked all the more easily by utilizing three stage power on the grounds that the voltage might be transmitted and conveyed over long distances. Power conversion and circulation frameworks utilize delicate frameworks to store the inrush current produced. At point when charging the dc link capacitor, a substantial transient current and voltage outings are brought on by high inrush current. These can result harm to the connection capacitor. LCL channel smoothen the output current and consequently minimizes the measure of current distortion factor to the lattice. As opposed to utilizing transformer, switching converter can additionally be utilized to step down the input voltage, in light of the fact that normally the output produced is at a different voltage level than the data. Furthermore, dc-dc converters are utilized to give noise reduction, power bus compensation, and so on (Konstantin, 1999).

Figure 3 shows control blocks for the dc-dc converter. The current present in each one phase is controlled by a PI controller and HF carrier. It is then given to dc-dc converter. Thus voltage in each one stage is controlled by PI current controller and it is given to dc-dc converter. By utilizing relative part, error could be lessened if there is any deviation in the ratio of the system, yet with decrease in stability. Integral part of the controller guarantees diminished steady state error without bargaining stability.

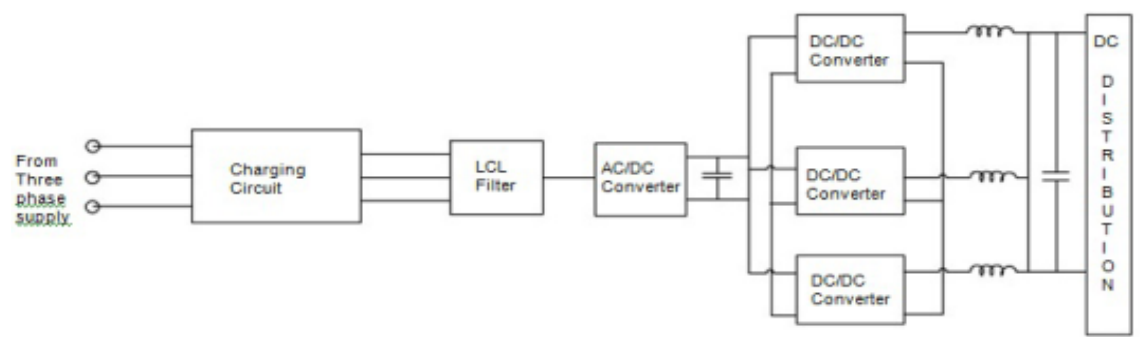

Figure 2. Block diagram of de distribution system 


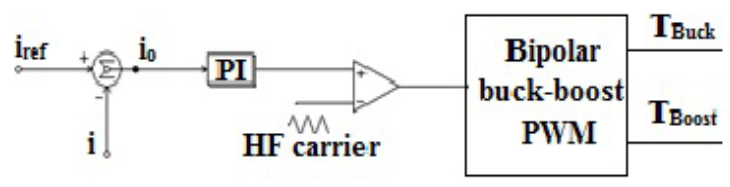

Figure 3. Control block for three phase dc-dc converter

The design methodology and implementation are presented in the forthcoming sections.

\section{Design of DC-DC Converter}

The design for two different modes namely buck and boost are presented in this section. The buck source voltage and the given load voltage are selected as $12 \mathrm{~V}$ and $9 \mathrm{~V}$ respectively. Duty cycle of the buck converter is 0.75 . When $12 \mathrm{~V}$ input voltage is given steady state dc voltage of $9 \mathrm{~V}$ is obtained. Similarly when the input voltage to the boost converter is $12 \mathrm{~V}$, the output is $40 \mathrm{~V}$, so that the duty ratio is 0.7 (Tse and Guldner, 1999; Woywode and Guldner, 2000).

\subsection{Buck Mode}

During the On period, the input voltage $\left(\mathrm{V}_{\mathrm{i}}\right)$ will come across the inductor, and a change in current $\left(\mathrm{I}_{\mathrm{L}}\right)$ will be there for a time period $(\Delta t)$ and it is given by

$$
\frac{\Delta I_{L}}{\Delta t}=\frac{V_{i}}{L}
$$

The values are chosen so that $\Delta \mathrm{I}_{\mathrm{Lon}}$ is equal to $\Delta \mathrm{I}_{\mathrm{Loff}}$. After on-period, the increase in $\mathrm{I}_{\mathrm{L}}$ is noted as,

$$
\begin{array}{r}
\Delta \mathrm{I}_{\mathrm{Lon}}=\frac{1}{\mathrm{~L}} \int_{0}^{\mathrm{DT}} \mathrm{V}_{\mathrm{i}} \mathrm{dt}=\frac{0.75 \times 9 \times 400 \times 10^{-6}}{400}=0.27 \mu \mathrm{A} \\
\Delta \mathrm{I}_{\text {Loff }}=\frac{1}{\mathrm{~L}} \int_{\text {ton }}^{\mathrm{T}} \mathrm{V}_{\mathrm{L}} \mathrm{dt}=\frac{-V_{0}}{\mathrm{~L}}=0.25 \mu \mathrm{A} \\
\left\{\begin{array}{c}
\mathrm{V}_{\mathrm{i}}-\mathrm{V}_{0} \mathrm{DT}-\mathrm{V}_{0}(1-\mathrm{D}) \mathrm{T}=0 \\
\mathrm{~V}_{0}-\mathrm{DV} \mathrm{V}_{\mathrm{i}}=0 \\
\mathrm{D}=0.75
\end{array}\right\} \\
\mathrm{C}_{\min }=\frac{(1-\mathrm{D}) \mathrm{V}_{0}}{8 \mathrm{~V}_{\mathrm{r}} \mathrm{L}_{\mathrm{f}}^{2}}=700 \mu \mathrm{F} \\
\mathrm{L}_{\mathrm{b}}=\frac{(1-\mathrm{D})^{2}}{2 \mathrm{f}}=360 \mu \mathrm{F}
\end{array}
$$

\subsection{Boost Mode}

To get the same ripple current the following design equations are used for boost mode.

$$
\begin{gathered}
\Delta \mathrm{I}_{\text {Loff }}=\frac{1}{\mathrm{~L}} \int_{\text {ton }}^{\mathrm{T}}\left(\mathrm{V}_{\mathrm{i}}-\mathrm{V}_{0}\right) \mathrm{dt}=\frac{12 \times 0.7 \times 400 \times 10^{-6}}{10000}=33.6 \mu \mathrm{A} \\
\Delta \mathrm{I}_{\text {Lon }}+\Delta \mathrm{I}_{\text {Loff }}=0 \\
\Delta \mathrm{I}_{\text {Lon }}+\Delta \mathrm{I}_{\text {Loff }}=\frac{V_{i} D T}{L}+\frac{\left(V_{i}-V_{0}\right)(1-D) T}{L}
\end{gathered}
$$




$$
\begin{gathered}
\frac{V_{i}}{V_{0}}=\frac{1}{(1-D)} \\
\mathrm{L}_{\mathrm{b}}=\frac{(1-\mathrm{D})^{2} D R}{2 \mathrm{f}}=360 \mu \mathrm{F} \\
\mathrm{C}_{\text {min }}=\frac{(1-\mathrm{D}) \mathrm{V}_{0}}{8 \mathrm{~V}_{\mathrm{r}} \mathrm{L}_{\mathrm{f}}^{2}}=700 \mu \mathrm{F}
\end{gathered}
$$

\section{Simulation of the Parallel Converter}

In the way of understanding the response of the converter controlled algorithm, a descriptive model of dc-dc converter scheme has analysed using the powerful tool MatLab/Simulink. The dc-dc converter and its performance has analysed for variation in the load $100 \Omega$ and $320 \Omega$ respectively. The parameters used for simulating dc-dc converter and its controller are shown in Table 1.

Table 1. Parameters used to design dc-dc converter

\begin{tabular}{cll}
\hline S. No & \multicolumn{1}{c}{ Parameters } & \multicolumn{1}{c}{ Values } \\
\hline 1 & Buck Inductor & $400 \mu \mathrm{H}$ \\
2 & Buck Input Voltage & $12 \mathrm{~V}$ \\
3 & Buck Output Voltage & $9 \mathrm{~V}$ \\
4 & Buck Capacitor & $780 \mu \mathrm{F}$ \\
5 & Switching frequency & $10 \mathrm{kHz}$ \\
6 & Buck Load resistance & $320 \Omega$ \\
7 & Boost capacitor & $800 \mu \mathrm{F}$ \\
8 & Boost Inductor & $400 \mu \mathrm{H}$ \\
9 & Boost Input Voltage & $12 \mathrm{~V}$ \\
10 & Boost Output Voltage & $40 \mathrm{~V}$ \\
11 & Boost Load resistance & $100 \Omega$ \\
\hline
\end{tabular}

The buck and boost inductance and capacitance have been selected as $400 \mu \mathrm{H}$ and $780 \mu \mathrm{F}$ respectively (as designed in Section 3.1 and Section 3.2). The simulation parameters are listed in Table 1and the corresponding results are presented in Figure 4 and Figure 5. Figure 4 (a) and Figure 4 (b) show the corresponding PWM pulses given to upper and lower switches. Figure 4 (c) corresponds to the source voltage given to the buck converter. Figure 4 (d) gives the variation of the output voltage $(9 \mathrm{~V})$ with reference to time for an input voltage of $12 \mathrm{~V}$ of the desired buck converter. Figure 5 (a) and Figure 5 (b) show the corresponding PWM pulses given to lower and upper switches. Figure 5 (c) corresponds to the source voltage given to the boost converter. Figure 5 (d) gives the variation of the output voltage $(34 \mathrm{~V})$ with reference to time for an input voltage of $12 \mathrm{~V}$ of the desired boost converter.
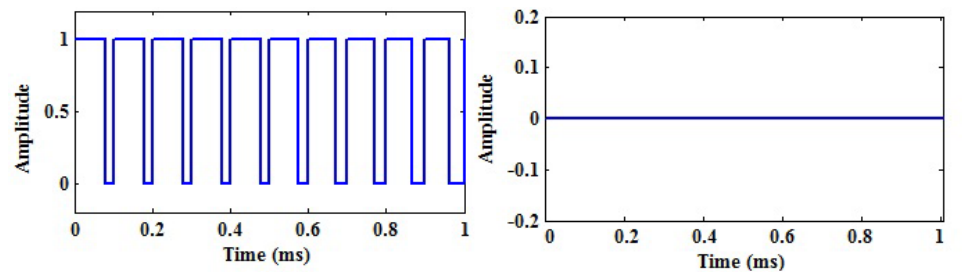

(a)
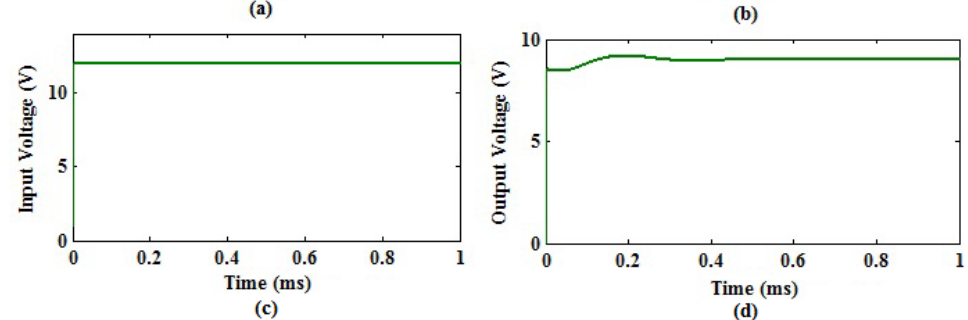

Figure 4. (a) Upper switches PWM, (b) Lower switches Pulse, (c) Buck input voltage, (d) Buck output voltage 


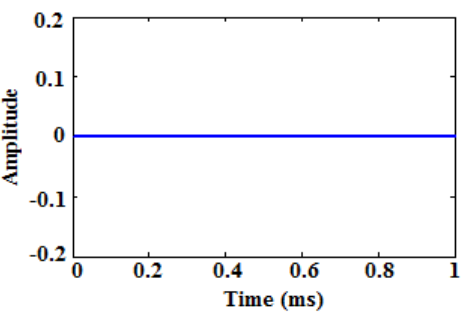

(a)

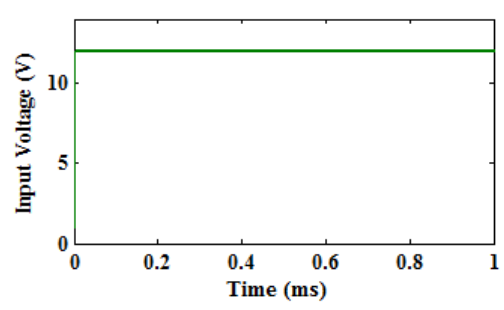

(c)

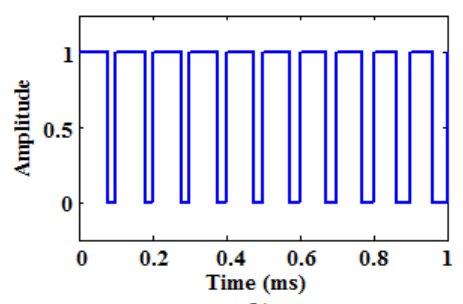

(b)

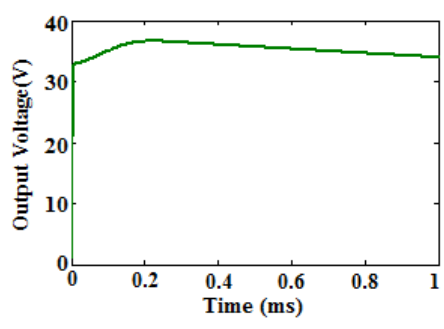

(d)

Figure 5. (a) Upper switches pulses (b) Lower switches PWM, (c) Boost input Voltage (d) Boost output voltage

\section{Hardware Implementation}

To ensure the effectiveness of proposed converter, $200 \mathrm{~W}$ laboratory prototype has been built for validating the simulation results. IRF 540 is used as control switches for the buck and boost circuits. The control signals fed to the gate of the switching devices are fed through gate driver circuit which acts as special isolator and also it supplies the 20mA current required for the micro controller. Microcontroller PIC16F877A could be programmed as timers and control the production line of the boost load and gate driver circuit. LM324 is used as signal conditioning device, does the filtering of unwanted pulses and boost up to the required data.

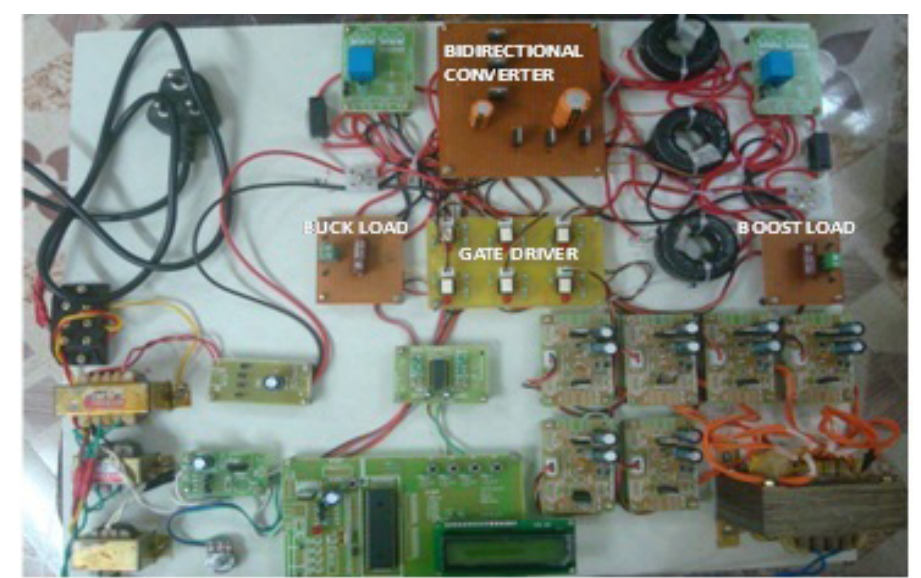

Figure 6. Hardware setup of the bidirectional buck-boost converter

\section{Results}

Figure 7 (a) denotes the steady state linear response when the input voltage varying from $10 \mathrm{~V}$ to $15 \mathrm{~V}$, for the buck converter. Figure 7 (b) specifies a constant voltage of $10 \mathrm{~V}$ when an input of $12 \mathrm{~V}$ is given. Figure 7 (c) \& Figure (d) shows the input current of $60 \mathrm{~mA}$ and output of $20 \mathrm{~mA}$. Figure 7 (e) shows the PWM for lower switches and Figure 7 (f) shows the reverse current flow of $40 \mathrm{~mA}$. Figure 8 (a) shows the steady output voltage of $38 \mathrm{~V}$, when the input voltage varies from $10 \mathrm{~V}$ to $15 \mathrm{~V}$ for the boost converter. Figure 8 (b) shows the constant voltage of $38 \mathrm{~V}$ when an input voltage of $16 \mathrm{~V}$ is given. Figure 8 (c) \& Figure 8 (d) shows the input current of $420 \mathrm{~mA}$ and output current of $50 \mathrm{~mA}$. Figure 8 (e) shows the PWM for upper switches and Figure 8 (f) shows the reverse current for $50 \mathrm{~mA}$. The ripples in output voltage and current waveforms can be reduced by putting properly designed snubber circuits. Voltage ripples of around $3.1 \%$ and current ripples of around $19 \%$ have been observed. 

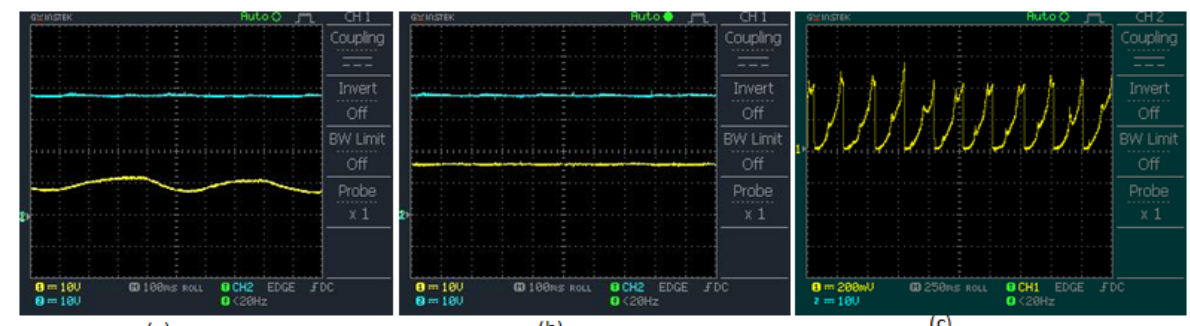

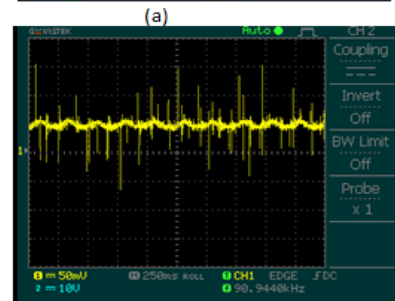

(d)

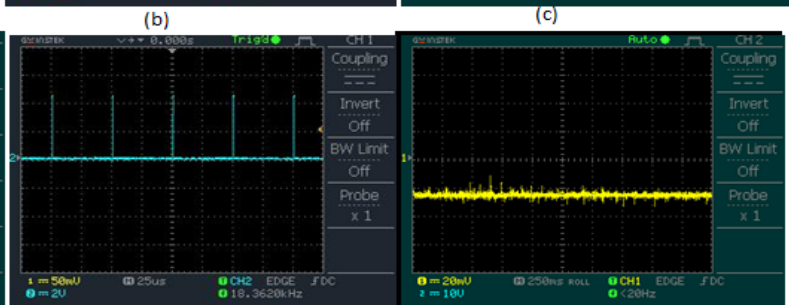

(e) (f)

Figure 7. (a) Output voltage for varying input, (b) Output voltage for constant input, (c) Input current, (d) Output current, (e) PWM output, (f) Reverse current for boost mode
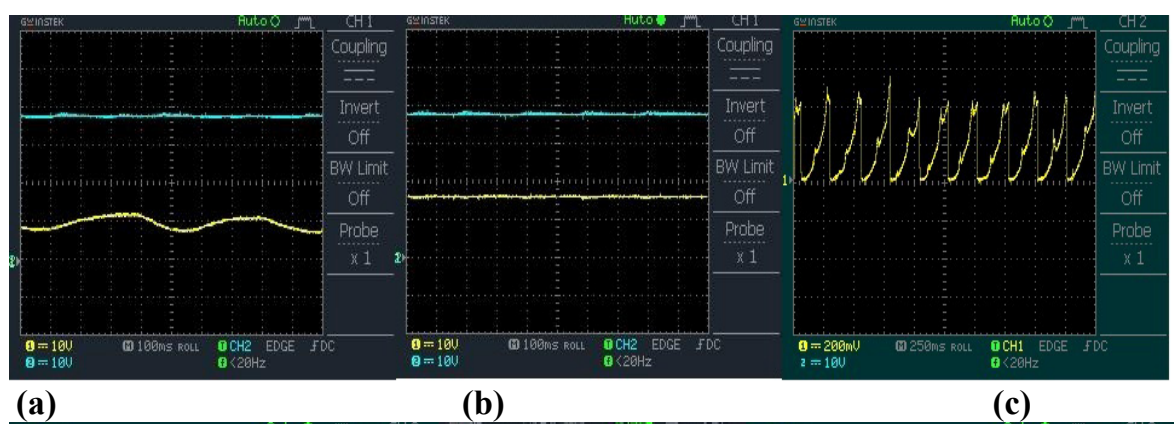

(b)

(c)

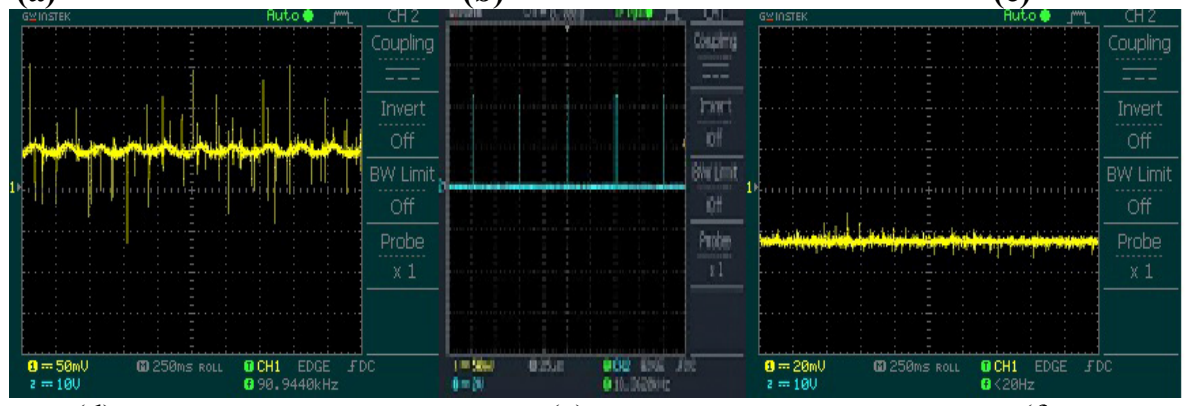

(d)

(e)

(f)

Figure 8. (a) Output voltage for varying input, (b) Output voltage for constant input, (c) Input current, (d) Output voltage at constant input, (e) PWM for output switches, (f) Varying input reverse current at buck mode

Huge inductance values have a tendency to expand the start-up time somewhat while little inductance permit the loop currents to increase to larger amounts before the switch is made to off position. Ferrite core inductors are proposed here. It is ought to be guaranteed that the saturation current rating of inductor is effective and it is to be utilized in a coil of low resistivity. Boost inductance is chosen with least permitted ripple and with least duty ratio, $\mathrm{D}$, at most extreme data voltage. With specified switching frequency, the value of boost inductor may be designed accordingly.

\section{Conclusion}

In this paper, a new control approach for parallel dc-dc converter is described. The analysis and design and implementation of the strategy have been done. This proves there is an equal distribution of current in each converter and there is a gain of steady voltage even under varying input conditions. The small capacitance connected with the dc-dc converter reduces the current flowing in the device and smoothens the ZVS operation of the switches. Improved transient response and reduction in ripple voltage has been tested by simulation and hardware results. This de distribution system can be fitted for switching facilities, in telecommunication systems, 
buildings and routers. A very less power loss and improved response in the generation and distribution is ensured by this system.

\section{References}

Adel, A., \& Elbaset, M. (2006). Study of Interconnecting Issues of Photovoltaic/Wind Hybrid System with Electric Utility Using Artificial Intelligence, (Doctoral dissertation), Faculty of Eng., Electrical Engineering Dept., Minia University. Retrieved from http://www.geocities.ws/dr_adel72/PhD_files/cover.pdf

Chi, H. C., Soo, C. S., Lee, H. J., Jung, C. H., Kim, H. S., \& Won, C. Y. (2012). Parallel System of Bidirectional DC/DC Converter for Improvement of Transient Response in DC Distribution System for Building Applications. IEEE vehicle power and propulsion conference, oct. 9-12, Seul, Korea. http://dx.doi.org/10.1109/VPPC.2012.6422609

Jaber, A. Q., \& Issa, B. G. (2000). Analysis of Soft-Switching DC-DC Converters, ISCAS 2000 - IEEE International Symposium on Circuits and Systems, 28-31, Geneva, Switzerland, 507-510. http://dx.doi.org/10.1109/ISCAS2000.856108.

Konstantin, P. L. (1999). Modeling and Analysis of A DC Power Distribution System In 21st Century Airlifters, (Master's thesis, M. Sc., Electrical Engineering Dept., Faculty of the Virginia Polytechnic Institute and State University) September 30, Blacksburg, Virginia. Retrieved from http://scholar.lib.vt.edu/theses/available/etd-102799-123413

Mohammad, H. R. (1993). Power Electronics: Circuits, Devices and Applications Prentice-Hall, Inc., Englewood Cliffs, Book, Second Edition.

Mohan, N., Undeland, T. M., \& Robbins, W. P. (1995). Power Electronics, Converters Applications and Design, John Wiley \& Sons, Inc., Book.

Tse, C. K., \& Guldner, K. M. (1999). Qualitative analysis and control of a DC-to-DC Boost Converter Operating in Discontinuous Mode, IEEE Transactions on Power Electronics, 5(3), 323-330. http://dx.doi.org/10.1109/63.56523

Williams, B. W. (1992). Power Electronics; Devices, Drivers, Applications and Passive Components, Book, Second Edition, Educational Low-Priced Books Scheme; ELBS.

Woywode, O., \& Guldner, H. (2000). Application of Statistical Analysis to DC-DC Converter, International Power Electronics Conference, IPEC, Tokyo, Japan. Retrieved from http://scholar.google.com/citations

\section{Copyrights}

Copyright for this article is retained by the author(s), with first publication rights granted to the journal.

This is an open-access article distributed under the terms and conditions of the Creative Commons Attribution license (http://creativecommons.org/licenses/by/3.0/). 